\title{
A formação inicial do pedagogo e o enfrentamento da medicalização na educação
}

\author{
Vânia Aparecida Calado', https://orcid.org/0000-0001-9529-5347 \\ Herculano Ricardo Campos², https://orcid.org /0000-0003-0366-9773
}

\begin{abstract}
Resumo
Estudantes com dificuldades na escolarização têm sido medicalizados, embora a principal causa dessas dificuldades seja deficiências do sistema educacional. Eles são duplamente punidos, com graves reflexos para sua vida escolar e social.Os professores, pela importância na escola,devem receber formação que aborde criticamente a medicalização, desde a formação inicial. Nessa perspectiva, realizou-se atividade pedagógica em disciplina de uma turma de graduação em Pedagogia de universidade de Natal/RN, visando transformar sua compreensão sobre a temática e pensara adoção do brincar como estratégia de enfrentamento do fenômeno. O diagnóstico inicial da compreensão dos estudantes revelou pouca ou nenhuma informação sobre medicalização e restrita compreensão do brincar, limitada à contribuição para a aprendizagem das crianças. A avaliação realizada depois de compartilhar diferentes brincadeiras, leitura de textos, poemas e estudos de casos sobre medicalização na educação revelou que essa mediação pedagógica contribuiu para qualificar a compreensão dos estudantes.
\end{abstract}

Palavras-chave: Medicalização; brincadeiras; pedagogia; graduação.

\section{The pedagogue's initial training and the confrontation of the medicalization in education}

\begin{abstract}
Students with difficulties in schooling have been medicalized, although the main cause of these difficulties is deficiencies of the educational system. They are doubly punished, with serious reflexes for their school and social life. Teachers, for their importance in school, should receive training that critically addresses medicalization, from initial training. From this perspective, a pedagogical proposal was developed with undergraduate students in Pedagogy at the University of Natal / RN, in the context of theoretical discipline, aiming at transforming their understanding of the theme and thinking about the adoption of play as a coping strategy of the phenomenon. The initial diagnosis of student understanding revealed little or no information about medicalization and restricted understanding of play, limited to the contribution to children's learning. The evaluation after sharing different jokes, reading texts, poems and case studies on medicalization in education revealed that this pedagogical mediation contributed to qualify students' understanding.
\end{abstract}

Keywords: Medicalization; play; pedagogy; University graduate.

\section{La formación inicial del pedagogo y el enfrentamiento de la medicalización en la educación}

\section{Resumen}

Los estudiantes con dificultades en la escolarización han sido medicalizados, aunque la principal causa de esas dificultades es deficiencias del sistema educativo. Ellos son doblemente castigados, con graves reflejos para su vida escolar y social. Los profesores, por la importancia en la escuela, deben recibir formación que aborde críticamente la medicalización, desde la formación inicial. En esta perspectiva, se realizó una propuesta pedagógica con clase de graduación en Pedagogía de universidad de Natal / RN, en el contexto de disciplina teórica, buscando transformar su comprensión sobre la temática y pensar la adopción del juego como estrategia de enfrentamiento del fenómeno. El diagnóstico inicial de la comprensión de los estudiantes reveló poca o ninguna información sobre medicalización y restringida comprensión del juego, limitada a la contribución al aprendizaje de los niños. La evaluación realizada después de compartir diferentes bromas, lectura de textos, poemas y estudios de casos sobre medicalización en la educación reveló que esa mediación pedagógica contribuyó a calificar la comprensión de los estudiantes.

Palabras clave: Medicalización; juegos; la pedagogía; graduación.

1 Universidade Potiguar - Laureate International Universities - Natal - RN - Brasil; vaniacaladopsi@gmail.com

2 Universidade Federal do Rio Grande do Norte - Natal - RN-Brasil; herculanorcampos@gmail.com 


\section{Introdução}

O processo de medicalização consiste na transformação de questões sociais, políticas e culturais, complexas e multifatoriais, em transtornos psiquiátricos ou outras doenças, a partir de um determinismo orgânico. Nesse processo, sentimentos e comportamentos são transformados em diagnósticos de patologias, cujo tratamento pode implicar no uso de medicamentos controlados. A educação também tem sido medicalizada, atingindo crianças e adolescentes com dificuldades em sua escolarização. Os obstáculos enfrentados por professores e alunos em função de um precário sistema educacional são desconsiderados e as causas são atribuídas a aspectos biológicos e individuais. (Moysés \& Collares, 2013).

Dados sobre venda e consumo de psicofármacos no Brasil revelam que houve crescimento de $300 \%$ na importação do metilfenidato de 2012 para 2013, 578kg e 1820kg, respectivamente. Na região Nordeste, a comparação da venda de caixas desse medicamento do primeiro semestre de 2009 com o primeiro semestre de 2014, mostra crescimento aproximado de $700 \%$, ou seja, de 7.760 para 55.665 caixas (Harayama, Gomes, Barros, Galindo, \& Santos, 2015). Esse medicamento é um estimulante do sistema nervoso central, prescrito para o tratamento do Transtorno do Déficit de Atenção e Hiperatividade, que se caracteriza por sintomas como agitação e impulsividade, e tem sido notadamente diagnosticado em crianças a partir dos 6 anos e adolescentes com queixas escolares (Moysés \& Collares, 2013).

Em face da constatação do problema na educação, com envolvimento significativo dos professores, considera-se necessário que a tematização dessa questão esteja presente nos cursos de formação inicial dos professores, de modo a contribuir com a elaboração de práticas pedagógicas não medicalizantes (Garrido \& Moysés, 2010). Nessa perspectiva, desenvolveu-se atividade que lançou mão de estratégias metodológicas que envolvem a mediação e o brincar. Para a realização da atividade foi considerado que o papel do professor no processo de aprendizagem é fundamental, pois atua como agente mediador, responsável por organizar as ações que possibilitam que o aluno crie e internalize o conhecimento social (Silva, Almeida, \& Ferreira, 2011).

Essas estratégias devem contribuir para romper com o discurso consolidado de que as causas para o fracasso escolar estão no organismo dos alunos e favorecer a descoberta de caminhos que potencializem as formas de aprender e enfrentar o fenômeno da medicalização na educação (Garrido \& Moysés, 2010).

O brincar pode se constituir importante instrumento na mediação, com vistas à construção do conhecimento em todos os níveis de ensino. É considerada uma atividade humana universal, está presente nos diferentes períodos históricos e se transforma com o tempo pelos próprios indivíduos, promovendo o prazer, a criatividade, as descobertas. $\mathrm{Na}$ formação inicial de professores o brincar é importante, entre outros aspectos, por favorecer a manifestação da sua dimensão humana e contribuir com a apropriação "da dimensão lúdica desse mundo adulto-educador, com possibilidades de profundas transformações nas intervenções com seus alunos" (Mendonça, 2008, p. 356).

Adotando o brincar como instrumento privilegiado, desenvolveu-se uma experiência educacional no contexto da formação inicial do pedagogo, em um componente curricular obrigatório do sexto período de um curso presencial noturno de Pedagogia, de uma universidade pública do Rio Grande do Norte. Os objetivos foram transformar a compreensão dos alunos sobre a temática e pensar a adoção do brincar como estratégia de enfrentamento do fenômeno. Os encontros ocorreram em aulas semanais, com duas horas cada, entre agosto e dezembro de 2016, no contexto de um componente curricular obrigatório do curso em questão. $\mathrm{O}$ trabalho foi desenvolvido em três etapas, todas registradas pelos alunos em três diferentes trabalhos escritos.

$\mathrm{Na}$ primeira etapa foi feito um diagnóstico sobre o que os estudantes conheciam acerca do fenômeno da medicalização e como compreendiam a importância do brincar na formação e na atuação do pedagogo, a partir da formulação das perguntas: Qual a importância do brincar para a atuação do pedagogo? Você sabe o que é medicalização da vida e da educação? Se sim, o que você sabe sobre esse tema? Apenas um estudante tinha informação acerca da medicalização na educação, mas que se referia apenas ao uso de medicamentos. A compreensão inicial sobre o brincar se limitou à contribuição para a aprendizagem dos alunos na infância (Mendonça, 2008).

$\mathrm{Na}$ segunda etapa, foram desenvolvidas atividades que exploraram o brincar de diferentes formas, tendo em vista a contribuição para a formação do pedagogo e sua atuação profissional. Os alunos assistiram ao documentário Tarja Branca (Renner, Nisti, Lobo, \& Rhoden, 2014); com o objetivo de relembrar a infância e se divertir (Mendonça, 2008), realizaram uma oficina de jogos e brincadeiras de sua infância, como pular corda, amarelinha, cobra cega, ioiô, pular elástico, cantigas de roda, detetive, adedonha; e leram textos que abordavam o tema teoricamente, com foco na formação do pedagogo e na prática pedagógica em qualquer nível e modalidade de ensino (Camargo \& Rosa, 2013; Mendonça, 2008; Meirelles, 2015). O registro do estudante 1 mostra que as atividades proporcionaram a vivência desses momentos de prazer, além de promoverem o resgate da memória da infância,que estava esquecida para a maior parte deles.

E1 - A felicidade proporcionada por cada atividade esteve estampada no rosto de cada colega e, de fato, embora enferrujados, foi mais fácil brincar e relembrar das brincadeiras do que nós esperávamos. Infelizmente, a muitos de nós, as obrigações da vida adulta surgiram de forma muito precoce, talvez por isso, nossa experiência em sala tenha sido tão prazerosa e tenha contribuído de forma tão significativa para um novo olhar do nosso exercício profissional, com relação a este tema.

A terceira e última etapa teve por objetivo aprofundar o conhecimento acerca da medicalização na educação. Os 
alunos leram poemas sobre medicalização extraídos da tese de Perez (2016), discutiram os estudos de caso abordados por Souza (2014), dados estatísticos sobre venda e consumo de psicofármacos (Harayama \& cols., 2015) e textos acadêmicos sobre o fenômeno (Leonardo \& Suzuki, 2016). Os alunos tinham pouca informação sobre os supostos transtornos do não aprender, acerca do uso de medicamentos e do envolvimento da indústria farmacêutica na potencialização do fenômeno, o que fazia com que naturalizassem o diagnóstico e a prescrição medicamentosa (Moysés \& Collares, 2013).

No final do processo de trabalho foi possível constatar que os estudantes, em comparação com suas opiniões no diagnóstico inicial, refletiram criticamente sobre o fenômeno da medicalização, revelando mudança de compreensão acerca do mesmo. A estudante 2 expressa muito bem essa mudança:

E2 - Já havia pensado a respeito deste tema em outras ocasiões... mas nunca com nenhuma profundidade ou ainda sem dar a devida atenção ao tema. É certamente um assunto intrigante que interessa a todos, professores, pais e sociedade de modo geral, e um assunto particularmente assustador...

Os registros dos estudantes 3 e 4 revelaram um conteúdo presente em quase todos os trabalhos escritos. Para eles, o processo de enfrentamento ao fenômeno da medicalização na educação deve envolver o professor e ter início pela compreensão crítica do mesmo. A superação da medicalização da educação exige uma escola e práticas pedagógicas humanizadas, focadas na diversidade e na singularidade dos indivíduos, ao invés de diagnosticar e rotular. O brincar surge como possibilidade:

E3 - ... mas é necessários a nós pedagogos entendermos urgentemente o que é ser gente e ser criança, entender que a escola e a educação não devem ser as bitolas de uma eugenia refinada, precisamos adotar uma postura diferente e isso começa em aceitar as diferenças que existem entre as pessoas, e superar a expectativa de diferenças na aparência sabendo que também existirão em relação aos temperamentos e aos comportamentos.

E4 - Ao invés de medicar as crianças na escola, por que não brincar? Vimos em nossas aulas que brincar é um excelente remédio!... A medicalização nas escolas é realmente um tema que precisa ser investigado, debatido e não esquecido e o pedagogo, juntamente com outros profissionais afins, não pode ser mero coadjuvante nessa discussão.

Considera-se que o caminho percorrido possibilitou a compreensão e reflexão crítica acerca do fenômeno da medicalização na educação e das possibilidades da atuação do pedagogo no enfrentamento deste, por meio de práticas pedagógicas mais humanizadas. Aprofundar a importância do brincar na formação inicial do pedagogo, a partir da mediação do professor, consistiu em estratégia pedagógica acertada, que promoveu a participação ativa de todos, de modo mais humanizado. Sugere-se a realização dessa estratégia em componente curricular que possibilite estágio para que seja possível aplicar as práticas pedagógicas elaboradas.

\section{Referências}

Camargo, P. S. A. S.; Rosa, E. C. (2013). A ludicidade como estratégia pedagógica na educação de jovens e adultos - EJA. Mimesis, 34(2), 219-232.

Harayama, R. M.; Gomes, J.; Barros, R.; Galindo, D.; Santos, D. (2015). Nota técnica: o consumo de psicofármacos no Brasil, dados do Sistema Nacional de Gerenciamento de produtos controlados, ANVISA (2007-2014). Fórum sobre Medicalização da Educação e da Sociedade.

Garrido, J.; Moysés, M. A. A. (2010) Um panorama nacional dos estudos sobre a medicalização da aprendizagem de crianças em idade escolar. In: Conselho Regional de Psicologia de São Paulo \& Grupo Interinstitucional Queixa Escolar (Orgs.), Medicalização de crianças e adolescentes: conflitos silenciados pela redução de questões sociais a doença de indivíduos (pp. 149-161). São Paulo, SP: Casa do Psicólogo.

Leonardo, N. S. T. \& Suzuki, M. A. (2016) Medicalização dos problemas de comportamento na escola: perspectivas de professores. Fractal, Rev. Psicol., v. 28 - n. 1, p. 46-54.

Mendonça, J. G. R. (2008). Formação de professores: a dimensão lúdica em questão. Cadernos da Pedagogia, 2(3), 253-263.

Meirelles, R. (Org.) (2015). Território do brincar. diálogo com escolas. São Paulo, SP: Instituto Alana. (Coleção território do brincar).

Moysés, M. A.; Collares, C. A. L. (2013). Controle e medicalização da infância. Desidades: Revista Eletrônica de Divulgação Científica na Área da Infância e Juventude, 1(1), 11-21.

Perez, E. C. de M. F. (2016). Medicalização e Educação: o entorpecimento da infância no cotidiano escolar. Tese de doutorado, Universidade de Sorocaba. Recuperado de http:// educacao.uniso.br/producao-discente/teses/Teses_2016/elaineperez.pdf

Renner, E.; Nisti, M.; Lobo, L. (Produtor); Rhoden, C. (Diretor). 2014. Tarja Branca (DVD). São Paulo: Maria Farinha Filmes.

Silva, S. M. C.; Almeida, C. M. D. C.; Ferreira, S. (2011). Apropriação cultural e mediação pedagógica: contribuições de Vigotski na discussão do tema. Psicologia em Estudo,16(2), 219-228.

Souza, B. de P. (2014) Puxando o tapete da medicalização do ensino: uma outra educação é possível. Nuances: Estudos sobre 
Educação, Presidente Prudente-SP, 25(1), p. 299-316, jan./ abr. 2014. Recuperado de http://revista.fct.unesp.br/index.php/ Nuances/article/viewFile/2733/2533

Recebido em: 13 de janeiro de 2017 Aceito em: 02 de março de 2017

License information: This is an open-access article distributed under the terms of the License (type CC-BY), which permits unrestricted use, distribution and reproduction in any medium, provided the original article is properly cited. 